\title{
SUBIEKTYWNA OCENA BÓLU U PACJENTÓW PO OPERACJACH KARDIOCHIRURGICZNYCH
}

\section{SUBJECTIVE ASSESSMENT OF POSTOPERATIVE PAIN IN THE PATIENTS AFTER HEART SURGERY}

\author{
Joanna Owsianowska, a, Anna Romacka², Sylwia Wieder-Huszla, b, Jolanta Wesołowska², \\ Katarzyna Karakiewicz-Krawczyk ${ }^{1, c}$, Marcin Sygut ${ }^{4}$, Anna Jurczak ${ }^{1, d}$ \\ ${ }^{1}$ Zakład Pielęgniarstwa Specjalistycznego, Wydział Nauk o Zdrowiu, Pomorski Uniwersytet Medyczny w Szczecinie \\ ${ }^{2}$ Studenckie Koło Naukowe, Zakład Pielegniarstwa Specjalistycznego, Wydział Nauk o Zdrowiu, Pomorski Uniwersytet Medyczny w Szczecinie \\ ${ }^{3}$ Zakład Dermatologii Estetycznej, Wydział Nauk o Zdrowiu, Pomorski Uniwersytet Medyczny w Szczecinie \\ ${ }^{4}$ Samodzielny Publiczny Szpital Kliniczny nr 2 w Szczecinie \\ ${ }^{a}$ https://orcid.org/0000-0001-9096-8477 \\ ${ }^{\mathrm{b}} \mathrm{https}: / /$ orcid.org/0000-0002-6084-5780 \\ ${ }^{c} \mathrm{https}: / /$ orcid.org/0000-0002-0606-5599 \\ ${ }^{\mathrm{d}}$ https://orcid.org/0000-0003-1935-5285
}

DOI: https://doi.org/10.20883/pielpol.2019.31

\section{STRESZCZENIE}

Wstęp. W okresie pooperacyjnym, pacjenci narażeni są na zwiększone odczuwanie bólu, co wpływa na stan psychofizyczny. Stopień odczuwania bólu pooperacyjnego jest determinowany przez szereg czynników, takich jak: przygotowanie do zabiegu, typ osobowości, wcześniejsze doświadczenia związane z bólem. Zadaniem wielospecjalistycznego leczenia dolegliwości bólowych staje się niwelowanie cierpienia fizycznego, poprawa komfortu psychicznego, szybszy powrót do sprawności i zapobieganie powikłaniom pooperacyjnym.

Cel. Celem pracy była próba subiektywnej oceny bólu pooperacyjnego. Materiał i metody. Badania przeprowadzono metodą sondażu diagnostycznego od lipca do października 2016 roku. Grupę badaną stanowiło 349 pacjentów hospitalizowanych w Klinice Kardiochirurgii SPSK Nr 2 w Szczecinie. W badaniach wykorzystano kwestionariusz autorskiej ankiety.

Wyniki. Wykazano korelację między stanem psychicznym chorych przed operacją, a nasileniem bólu pooperacyjnego. Najsilniejszy ból badani odczuwali w 3-4 dobie, a następnie w 1-2 dobie po zabiegu operacyjnym w trakcie poruszania się. Za okres najmniejszego natężenia bólu po operacji serca respondenci wskazywali piątą dobę po przebytym zabiegu. Większość ankietowanych (194 osoby) odczuwało przed zabiegiem podenerwowanie i napięcie. W ocenie stanu psychicznego przygnębienie i trudności z koncentracją deklarowało 58 badanych, natomiast spokój i opanowanie 94 osoby.

Wnioski. 1) Stan psychiczny i przygotowanie pacjentów do zabiegu operacyjnego wpływa w sposób istotny na zachowanie chorych po operacji. 2) Zarówno prawidłowe leczenie bólu pooperacyjnego, jego systematyczna ocena, jak i troskliwa opieka zespołu pielęgniarskiego, wpływają na pozytywny wizerunek szpitala w sondażach oraz podniesienie jakości świadczonych usług medycznych. 3) Wskazane jest prowadzenie systematycznych szkoleń dla personelu pielęgniarskiego i lekarskiego z zakresu terapii bólu celem podniesienia świadomości dotyczącej niekorzystnych skutków bólu ostrego.

SŁOWA KLUCZOWE: pacjent, kardiochirurgia, ból pooperacyjny, opieka pielęgniarska.

\begin{abstract}
Introduction. In the postoperative period, patients are exposed to increased pain, which affects their psychophysical condition. The degree of perceived post-operative pain is determined by a number of factors, including: preparation of the patient for surgery, type of personality, previous experience related to pain. The task of multidisciplinary treatment of pain is to eliminate physical suffering, improve mental comfort, as well as to assist in faster recovery and prevention of dangerous postoperative complications.

Aim. The aim of the study was the attempt of a subjective assessment of postoperative pain.

Material and methods. The research was conducted using the diagnostic survey method from July to October 2016. The study group consisted of 349 patients hospitalized in the Department of Cardiac Surgery of the Independent Public Clinical Hospital No. 2 in Szczecin. The research used the author's questionnaire.

Results. A correlation between the mental state of patients before surgery and the intensity of postoperative pain was demonstrated. The strongest pain was felt on the 3-4th day, and then on the first or second day after surgery while moving. The respondents indicated that the lowest intensity of pain was experienced on the fifth day after surgery. Most of the respondents (194 people) felt nervousness and tension before the procedure. In the assessment of mental states, depression and difficulties with concentration were declared by 58 subjects, while calmness and self-control reported by 94 people.

Conclusions. 1) The mental state and preparation of patients for surgery significantly affect the behaviour of patients after surgery. 2) Both correct treatment of post-operative pain, its systematic assessment, and the careful care of the nursing team, affect the positive image of the hospital in surveys and improve the quality of medical services provided. 3) It is advisable to conduct systematic training for nursing and medical staff in the field of pain therapy in order to raise awareness of the adverse effects of acute pain.
\end{abstract}

KEYWORDS: patient, cardiac surgery, postoperative pain, nursing care. 


\section{Wprowadzenie}

Ból pooperacyjny stanowi pewien rodzaj bólu ostrego, pojawiającego się wówczas, gdy przestaje działać śródoperacyjna analgezja. Jego intensywność zależna jest od rozległości zabiegu operacyjnego, natomiast źródłem są uszkodzone tkanki. Ból jest odczuciem subiektywnym, przeżywanym jako zjawisko somatyczne. W przypadku bardzo rozległych operacji oprócz bólu somatycznego pojawia się również ból trzewny, wywołany skurczem mięśni gładkich otaczających miejsce urazu, a także zmianami zapalnymi wywołanymi przez uraz, jakim staje się operacja [1]. Zabiegi kardiochirurgiczne, podobnie jak torakochirurgiczne, należą do operacji bardzo rozległych, a czas ich trwania zależy od rodzaju zabiegu. Głównym czynnikiem bólu u pacjentów po operacjach serca staje się rozległa rana pooperacyjna na klatce piersiowej, związana z przecięciem mostka na całej jego długości oraz obecnością drenów śródoperacyjnych i/lub opłucnowych, które odprowadzają wydzielinę bezpośrednio po zabiegu. Ból pooperacyjny nie spełnia roli użytecznej, a leczony w sposób nieefektywny może wywołać szereg nieprawidłowych reakcji fizjologicznych, prowadzących do powstania zaburzeń, a w późniejszym okresie powikłań, co wywiera niekorzystny wpływ na stan pacjenta i jego funkcjonowanie [2]. Walka z bólem należy do priorytetowych zadań personelu opiekującego się pacjentami po zabiegach kardiochirurgicznych, szczególnie tych rozległych i obciążonych dużym ryzykiem powikłań [3]. Ocena natężenia dolegliwości bólowych oraz regularne podawanie zleconych leków przeciwbólowych ma spowodować u pacjenta uczucie komfortu i ułatwić proces zdrowienia poprzez zmniejszenie ryzyka groźnych powikłań pooperacyjnych ogólnoustrojowych i miejscowych [4]. Najważniejszy element skutecznej walki z bólem stanowi jego pomiar, do najczęściej stosowanych skal oceniających natężenie dolegliwości bólowych należą między innymi skale: numeryczna (NRS), wzrokowoanalogowa (VAS) oraz słowna (VRS) [5].

\section{Cel pracy}

Celem pracy była próba subiektywnej oceny bólu pooperacyjnego.

\section{Materiał}

Grupę badaną stanowiło 349 pacjentów (98 kobiet, 251 mężczyzn) hospitalizowanych w Klinice Kardiochirurgii SPSK Nr 2 w Szczecinie. Przeprowadzone badania nie wymagały zgody Komisji Bioetycznej. Kryterium doboru do grupy badanej stanowił stan po odbytym zabiegu operacyjnym: wymiana zastawki aortalnej (AVR), pomostowanie aortalno-wieńcowe (CABG), plastyka zastawki mitralnej (MVP), pomostowanie tętnic wieńcowych bez zastosowania krążenia pozaustrojowego (OPCAB), przezcewnikowe wszczepienie zastawki aortalnej (TAVI), stentgraft aorty brzusznej, rozejście się ran pooperacyjnych lub infekcji pooperacyjnej z koniecznością terapii rany z użyciem opatrunku pod ciśnieniem (VAC). Badania przeprowadzano w piątej i szóstej dobie po zabiegu operacyjnym u pacjentów w ustabilizowanym stanie ogólnym.

\section{Metody}

Badania przeprowadzono metodą sondażu diagnostycznego w okresie od lipca do października 2016 roku w oparciu o wykorzystanie autorskiego kwestionariusza ankiety, który składał się z 24 pytań o charakterze zamkniętym. Pytania dotyczyły oceny bólu pooperacyjnego, dolegliwości towarzyszących bólowi i stanu psychicznego oraz jakości opieki pielęgniarskiej w aspekcie zwalczania bólu i satysfakcji z proponowanego leczenia przeciwbólowego (zarówno metodami farmakologicznymi, jak i niefarmakologicznymi). Natężenie dolegliwości bólowych respondenci oceniali według skali słownej, w której 0 - oznaczało brak bólu, a 5 - najsilniejsze dolegliwości bólowe. Analizę statystyczną zebranego materiału wykonano w programie Statistica 12. Do oceny pytań ankietowych w skali pomiarowej porządkowej w zależności od płci zastosowano test U Manna-Whitneya. Analizę zależności przeprowadzono z zastosowaniem korelacji rang Spearmana. $W$ analizach jako istotne przyjęto efekty, dla których wartość prawdopodobieństwa p była mniejsza od przyjętego poziomu istotności 0,05 $(p<0,05)$.

\section{Wyniki}

Najliczniejsza grupa pacjentów, tj. 181 osób (51,86\%), odczuwała najsilniejsze dolegliwości bólowe w 3-4 dobie po zabiegu kardiochirurgicznym. U 163 ankietowanych (46,71\%) najbardziej dotkliwy ból wystąpił w 1-2 dobie pooperacyjnej. Tylko 5 osób spośród badanej grupy deklarowało odczuwanie najsilniejszego bólu w kolejnych dobach po przebytym zabiegu (Tabela 1).

Tabela 1. Okres występowania bólu pooperacyjnego o największym nasileniu

Table 1. Periods when the most severe postoperative pain occurs

\begin{tabular}{|c|c|c|c|c|c|c|c|c|}
\hline \multirow[t]{2}{*}{ Płeć/Sex } & \multicolumn{2}{|c|}{$\begin{array}{l}1 \text { doba po op- } \\
\text { eracji/the first } \\
\text { twenty-four } \\
\text { hours follow- } \\
\text { ing surgery }\end{array}$} & \multicolumn{2}{|c|}{$\begin{array}{c}\text { 3-4 doba } \\
\text { po operacji/ } \\
\text { the third and } \\
\text { fourth day } \\
\text { following sur- } \\
\text { gery }\end{array}$} & \multicolumn{2}{|c|}{$\begin{array}{l}\text { Kolejne doby } \\
\text { po operacji/ } \\
\text { subsequent } \\
\text { days follow- } \\
\text { ing surgery }\end{array}$} & \multicolumn{2}{|c|}{ Razem/Total } \\
\hline & $\mathrm{n}$ & $\%$ & $\mathbf{n}$ & $\%$ & $\mathbf{n}$ & $\%$ & $n$ & $\%$ \\
\hline Kobieta/Woman & 40 & 40,82 & 56 & 57,14 & 2 & 2,04 & 98 & 100 \\
\hline Mężczyzna/Man & 123 & 49,00 & 125 & 49,80 & 3 & 1,20 & 251 & 100 \\
\hline Ogółem/Total & 163 & 46,71 & 181 & 51,86 & 5 & 1,43 & 349 & 100 \\
\hline
\end{tabular}

$\mathrm{n}$ - liczba/number, \% - procent/percentage

Źródło: opracowanie własne

Source: author's own analysis 
Najliczniejsza grupa ankietowanych $(38,40 \%)$ oceniła natężenie dolegliwości bólowych po zabiegu na poziomie 3 w skali od 0 do 5 . Na natężenie dolegliwości na poziomie 2 - wskazywało 36,39\% respondentów. Najsilniejsze dolegliwości bólowe deklarowało 2,00\% badanych, natomiast nikt z ankietowanych nie deklarował braku dolegliwości bólowych po zabiegu (Tabela 2).

Tabela 2. Ocena natężenia dolegliwości bólowych z uwzględnieniem płci badanych

Table 2. Assessment of pain severity with regard to sex

\begin{tabular}{|c|c|c|c|c|c|c|c|c|c|c|c|c|}
\hline \multirow{3}{*}{ Płeć/Sex } & \multicolumn{10}{|c|}{ Skala natężenia dolegliwości bólowych/Pain severity scale } & \multirow{2}{*}{\multicolumn{2}{|c|}{$\begin{array}{c}\text { Razem/ } \\
\text { Total }\end{array}$}} \\
\hline & & 0 & & 1 & 2 & & 3 & 4 & & 5 & & \\
\hline & $n$ & $\%$ & $\mathrm{n}$ & $\%$ & $\%$ & $n$ & $\%$ & $\mathrm{n} \quad \%$ & $n$ & $\%$ & $n$ & $\%$ \\
\hline $\begin{array}{c}\text { Kobieta/ } \\
\text { Woman }\end{array}$ & 0 & 0,00 & 3 & 3,06 & 3232,65 & 43 & 43,88 & 17 17,35 & 3 & 3,06 & 98 & 100 \\
\hline $\begin{array}{l}\text { Mężczy- } \\
\text { zna/Man }\end{array}$ & 0 & 0,00 & 15 & 5,98 & $95 \quad 37,85$ & 91 & 36,25 & 4618,33 & 4 & 1,59 & 251 & 100 \\
\hline $\begin{array}{c}\text { Ogółem/ } \\
\text { Total }\end{array}$ & 0 & 0 & 18 & 5,16 & 12736,39 & 134 & 38,40 & 6318,05 & 7 & 2,00 & 349 & 100 \\
\hline \multicolumn{13}{|c|}{ n-liczba/number, \% - procent/percentage } \\
\hline \multicolumn{12}{|c|}{ Źródło: opracowanie własne } & \\
\hline
\end{tabular}

Prawie połowa, tj. 47,56\%, pacjentów rzadko informowała personel o występujących dolegliwościach bólowych, wynikało to z ich przekonania, że tego typu symptom jest nieunikniony. Częste informowanie o bólu w ciągu doby potwierdziło $33,24 \%$ respondentów. Tylko $19,20 \%$ badanych wskazało, że nie występowały u nich dolegliwości bólowe związane z zabiegiem operacyjnym (Tabela 3).

Tabela 3. Informowanie personelu o dolegliwościach bólowych Table 3. Informing the staff about pain complaints

\begin{tabular}{cccccccc}
\hline \multicolumn{8}{c}{ Częstość informowania o dolegliwościach } \\
bólowych/ \\
The frequency of informing the staff about \\
pain complaints
\end{tabular}

$\mathrm{n}$ - liczba/number, \% - procent/percentage

Źródło: opracowanie własne

Source: author's own analysis
Najliczniejsza grupa respondentów, 66,19\%, potwierdziła, że po zabiegu operacyjnym personel dokonywał pomiarów natężenia dolegliwości bólowych. Stosunkowo liczną grupę $(28,65 \%)$ reprezentowali badani, którzy nie byli świadomi wykonywania pomiarów. Tylko według nielicznej grupy pacjentów, 5,16\%, personel nie dokonywał pomiaru natężenia dolegliwości bólowych (Tabela 4).

Tabela 4. Pomiar natężenia bólu pooperacyjnego w opinii ankietowanych Table 4. Measurements of postoperative pain according to the patients

\begin{tabular}{|c|c|c|c|c|c|c|c|c|}
\hline \multirow{3}{*}{ Płeć/Sex } & \multicolumn{6}{|c|}{$\begin{array}{l}\text { Czy wg pacjentów przeprowadzono } \\
\text { u nich pomiary bólu pooperacyjnego?/ } \\
\text { Was postoperative pain measured } \\
\text { according to the patients? }\end{array}$} & \multirow{2}{*}{\multicolumn{2}{|c|}{ Razem/Total }} \\
\hline & \multicolumn{2}{|c|}{ Tak/Yes } & \multicolumn{2}{|c|}{$\mathrm{Nie} / \mathrm{No}$} & \multicolumn{2}{|c|}{$\begin{array}{l}\text { Nie wiem/ } \\
\text { Idon't know }\end{array}$} & & \\
\hline & $\mathrm{n}$ & $\%$ & $\mathrm{n}$ & $\%$ & $\mathrm{n}$ & $\%$ & $n$ & $\%$ \\
\hline Kobieta/Woman & 70 & 71,43 & 2 & 2,04 & 26 & 26,53 & 98 & 100 \\
\hline Mężczyzna/Man & 161 & 64,14 & 16 & 6,38 & 74 & 29,48 & 251 & 100 \\
\hline Ogółem/Total & 231 & 66,19 & 18 & 5,16 & 100 & 28,65 & 349 & 100 \\
\hline
\end{tabular}

$\mathrm{n}$ - liczba/number, \% - procent/percentage

Źródło: opracowanie własne

Source: author's own analysis

Liczna grupa badanych $(71,84 \%)$ oceniała zastosowanie leczenia przeciwbólowego po zabiegu operacyjnym jako dobre. Całkowite ustąpienie dolegliwości bólowych na skutek leczenia zadeklarowało 21,26\% pacjentów. Tylko 6,90\% respondentów uznało prowadzone leczenie przeciwbólowe za mało skuteczne (Tabela 5).

Tabela 5. Skuteczność leczenia przeciwbólowego w opinii ankietowanych Table 5. Effectiveness of analgesic treatment according to the surveyed

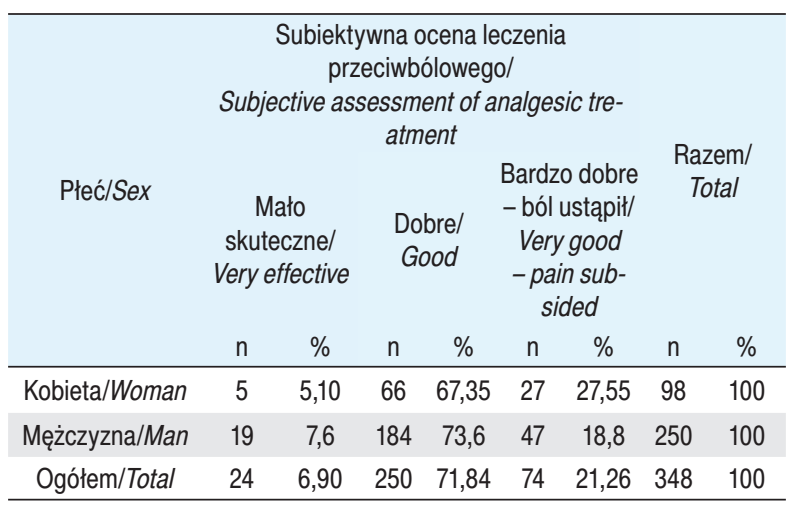

$\mathrm{n}$ - liczba/number, \% - procent/percentage

Źródło: opracowanie własne

Source: author's own analysis

Przeprowadzona analiza wykazała istotną statystycznie zależność pomiędzy nasileniem dolegliwości bólowych w kolejnych dobach po zabiegu, a oceną skuteczności leczenia przeciwbólowego $(\mathrm{p}<0,05)$ (Rycina 1). 


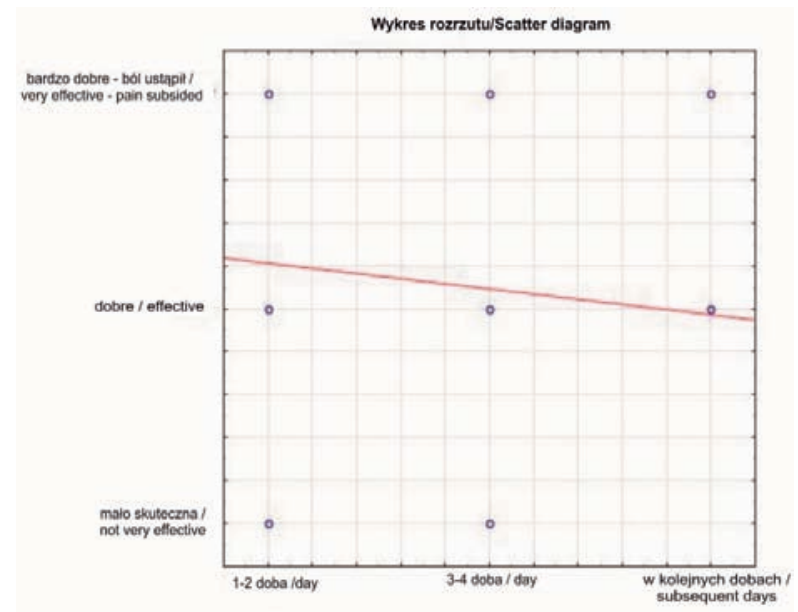

Rycina 1. Ocena skuteczności leczenia przeciwbólowego Figure 1. Assessment of the effectiveness of analgesic treatment

Źródło: opracowanie własne

Source: author's own analysis

Wśród najskuteczniejszych pozafarmakologicznych działań przyczyniających się do niwelowania dolegliwości bólowych ankietowani wymienili: okazywanie zainteresowania i zrozumienia pacjentowi $(38,97 \%)$, ułożenie w wygodnej pozycji w tym stabilizacja mostka w trakcie kaszlu (26,65\%), rozmowę (17,48\%), umiejętną zmianę opatrunków (16,90\%) (Tabela 6).

Tabela 6. Pozafarmakologiczne działania zmniejszające dolegliwości bólowe

Table 6. Non - pharmacological pain management

\begin{tabular}{|c|c|c|c|c|c|c|c|c|c|c|}
\hline \multirow[t]{2}{*}{ Płeć/Sex } & \multicolumn{2}{|c|}{$\begin{array}{c}\text { Rozmowa/ } \\
\text { Conversa- } \\
\text { tion }\end{array}$} & \multicolumn{2}{|c|}{$\begin{array}{c} \\
\text { Okazywanie } \\
\text { zaintereso- } \\
\text { wania } \\
\text { i zrozumie- } \\
\text { nia/ } \\
\text { Showing } \\
\text { interest and } \\
\text { empathy }\end{array}$} & \multicolumn{2}{|c|}{$\begin{array}{l}\text { Ułożenie w wy- } \\
\text { godnej pozycji } \\
\text { (stabilizacja } \\
\text { mostka przy } \\
\text { kaszlu)/Putting } \\
\text { a patient in a } \\
\text { comfortable } \\
\text { position (stabi- } \\
\text { lization of the } \\
\text { sternum during } \\
\text { coughing) }\end{array}$} & \multicolumn{2}{|c|}{$\begin{array}{l}\text { Umiejętna } \\
\text { zmiana } \\
\text { opatrunku/ } \\
\text { Skilled re- } \\
\text { placement of } \\
\text { a dressing }\end{array}$} & \multicolumn{2}{|c|}{$\begin{array}{c}\text { Razem/ } \\
\text { Total }\end{array}$} \\
\hline & $\mathrm{n}$ & $\%$ & $\mathrm{n}$ & $\%$ & $\mathrm{n}$ & $\%$ & $n$ & $\%$ & $\mathrm{n}$ & $\%$ \\
\hline $\begin{array}{l}\text { Kobieta/ } \\
\text { Woman }\end{array}$ & 16 & 16,33 & 39 & 39,80 & 31 & 31,63 & 12 & 12,24 & 98 & 100 \\
\hline $\begin{array}{c}\text { Mężczyzna/ } \\
\text { Man }\end{array}$ & 45 & 17,92 & 97 & 38,65 & 62 & 24,70 & 47 & 18,73 & 251 & 100 \\
\hline $\begin{array}{c}\text { Ogółem/ } \\
\text { Total }\end{array}$ & 61 & 17,48 & 136 & 38,97 & 93 & 26,65 & 59 & 16,90 & 349 & 100 \\
\hline
\end{tabular}

$\mathrm{n}$ - liczba/number, \% - procent/percentage

Źródło: opracowanie własne

Source: author's own analysis

Przeprowadzona analiza wykazała istotną statystycznie zależność pomiędzy stanem psychicznym pacjentów, a umiejscowieniem bólu pooperacyjnego $(p<0,05)$ (Rycina 2).

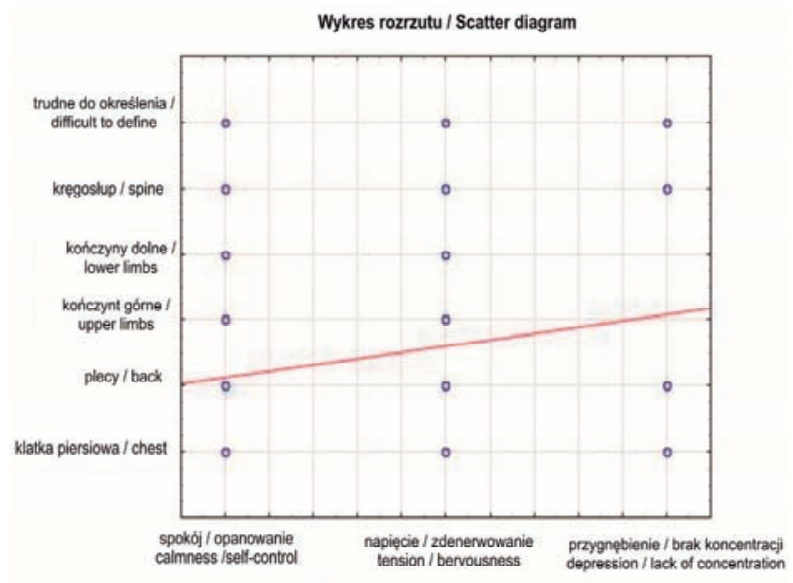

Rycina 2. Korelacja między stanem psychicznym chorych, a umiejscowieniem bólu pooperacyjnego

Figure 2. Correlation between the patients' mental status and the location of postoperative pain

Źródło: opracowanie własne

Source: author's own analysis

\section{Dyskusja}

Zabieg operacyjny wywołuje szereg implikacji natury psychicznej, emocjonalnej i fizycznej. Pacjenci hospitalizowani z powodu chorób kardiologicznych stanowią specyficzną grupę chorych. Wróblewska i wsp. [6] wskazują, że konieczność hospitalizacji, szczególnie w grupie pacjentów po 60. roku życia stanowi ogromne obciążenie i wywołuje zmiany zarówno w sferze fizycznej, jak i psychicznej, które manifestują się nadmiernym stresem, lękiem, a nawet mogą doprowadzić do wystąpienia zaburzeń depresyjnych. W przeprowadzonych badaniach własnych zdenerwowanie i napięcie związane z hospitalizacją prezentowało 55,59\% pacjentów a $16,32 \%$ odczuwało przygnębienie i miało problemy z koncentracją. Według Khan [7] stan ten wynika z istnienia samej choroby, która w wielu przypadkach utrudnia lub uniemożliwia pacjentom funkcjonowanie psychospołeczne i pełnienie cenionych ról społecznych. Według autora poziom lęku ma ścisły związek z czasem trwania choroby somatycznej, z kolei lęk przed urazem, jakim jest operacja, stanowi jeden z czynników mających wpływ na zachowania jednostki w okresie przed- i pooperacyjnym. Nasilenie lęku, myślenie depresyjne wpływają negatywnie na przebieg okresu pooperacyjnego, a w tym na wzrost intensywności bólu i wzrost liczby powikłań po operacji kardiochirurgicznej.

Zespół Bajurna [8] dowodzi, że szczególną grupę pacjentów stanowią osoby prezentujące przygnębienie i brak koncentracji, gdyż nie zapamiętują one wielu istotnych i ważnych z punktu widzenia przygotowania do 
operacji faktów, często prosząc o ponowne powtarzanie tych samych informacji. Poziom stresu i lęk przed hospitalizacją u tych chorych jest tak duży, że wpływa w sposób istotny na zapamiętywanie informacji dotyczących okresu przed i pooperacyjnego. W badaniach Kuciel-Lewandowskiej i wsp. [9] lęk występował u $80 \%$ chorych, a objawy depresyjne u $30 \%$ badanych. Wyniki zespołu Falkowskiej [10] wykazują, że dla 76\% badanych kwestia bólu stanowi ważny element hospitalizacji.

Badania własne pokazały, że największe natężenie bólu pooperacyjnego u pacjentów kardiochirurgicznych występowało w 3-4 dobie pooperacyjnej (51,86\%), a następnie w 1-2 dobie (46,71\%). Badania Szczudłowskiego i wsp. [11] przeprowadzone wśród pacjentów po operacji serca dowiodły, że największe nasilenie dolegliwości bólowych występowało w 1., 2. i 3. dobie po operacji. Z kolei w badaniach Zalewskiej-Puchały i wsp. [12] przeprowadzanych w grupie pacjentów po torakotomii bocznej wykonanej z powodu nowotworu płuca, najsilniejsze dolegliwości bólowe podczas poruszania się i głębokiego oddechu występowały w 2. dobie pooperacyjnej. Deneka w wsp. [13] uważa, że ból w klatce piersiowej może być spowodowany nie tylko samym zabiegiem operacyjnym, ale również chorobami współtowarzyszącymi, do których należą między innymi urazy klatki piersiowej, odma lub krwiak opłucnej. Bloch i wsp. [14] twierdzą, że sam zabieg operacyjny nie tylko wiąże się z bólem powstałym na skutek cięcia chirurgicznego, ale u blisko 50\% chorych dochodzi również do zmniejszenia zakresu ruchów w obrębie stawów kręgosłupa i znacznego zmniejszenia pojemności życiowej płuc, efektem czego są problemy z oddychaniem. Zespół Sokołowskiej [15] przeprowadził badania 112 pacjentów, którzy poddani byli zabiegom ortopedycznym. Wyniki badania pokazały, że w pierwszej dobie pooperacyjnej 80,36\% pacjentów odczuwało ból określany jako łagodny, a tylko 7,14\% określało dolegliwości jako silne. W badaniu tym zdecydowana większość pacjentów, 75,00\%, twierdziła, że ból odczuwany po operacji był silniejszy od spodziewanego [15].

Badania własne potwierdzają, że w trakcie hospitalizacji w walce z bólem po przebytym zabiegu operacyjnym pacjenci doceniają działania niefarmakologiczne podejmowane przez personel pielęgniarski. Za najważniejsze uznali bowiem okazanie zrozumienia i zainteresowanie, a także układanie w wygodnej pozycji z nauczeniem stabilizowania klatki piersiowej w trakcie kaszlu i podnoszenia się, delikatną, atraumatyczną zmianę opatrunków oraz rozmowę. Według Sochackiej i wsp. [16] pielęgniarki są osobami przebywającymi najdłużej z pacjentem i jednocześnie mającymi najczęstszy kontakt, a poprzez podejmowane działania zapewniają choremu poczucie bezpieczeństwa i komfort psychofizyczny.
Lisowska i wsp. [17] wskazuje, że przy prawidłowym doborze terapii przeciwbólowej niezbędnym elementem staje się prawidłowa komunikacja zarówno w zespole terapeutycznym, jak i na poziomie personel - pacjent. Badania Jurczak i wsp. [18] pokazały, że pacjenci najniżej ocenili działania dotyczące informowania o sposobach zwalczania bólu, co świadczy o nieprawidłowościach w zakresie relacji interpersonalnych między personelem a pacjentami.

Efektywne leczenie dolegliwości bólowych jest jednym z podstawowych praw pacjenta, co z kolei powoduje, że pielęgniarki, jako osoby spędzające najwięcej czasu z chorym, powinny być kompetentne w zakresie zwalczania bólu. Jednym z podstawowych zadań jest więc identyfikacja i prowadzenie wnikliwej obserwacji pacjentów tak, aby leczenie przeciwbólowe zastosować w określonym czasie. Bardzo istotne znaczenie ma zarówno lokalizacja, jak i określenie charakteru, natężenia czasu trwania i objawów, które towarzyszą występowaniu bólu [19].

\section{Wnioski}

1. Stan psychiczny i przygotowanie pacjentów do zabiegu operacyjnego, wpływa w sposób istotny na zachowanie chorych po operacji.

2. Zarówno prawidłowe leczenie bólu pooperacyjnego, jego systematyczna ocena, jak i troskliwa opieka zespołu pielęgniarskiego, wpływają na pozytywny wizerunek szpitala w sondażach oraz podniesienie jakości świadczonych usług medycznych.

3. Wskazane jest prowadzenie systematycznych szkoleń dla personelu pielęgniarskiego i lekarskiego z zakresu terapii bólu, celem podniesienia świadomości dotyczącej niekorzystnych skutków bólu ostrego.

\section{Piśmiennictwo}

1. Czernikiewicz A. Ból psychogenny. Nowa Medycyna. 2002; 5: 3-5.

2. Korytkowska A, Rokosz K, Kula A. Doznania bólowe pacjentów po zabiegu kardiochirurgicznym. W: Makiełło-Jarża G (red.). Ból i cierpienie. Kraków: Acta Academiae Modrevianae; 2011. 139-143.

3. Larysz A, Czapla K, Copik I. Nowoczesna terapia przeciwbólowa. Ból jako piąty parametr życiowy. Mag Pielęg Położ. 2013; 6: 40-42.

4. Żołnowska A. Leczenie bólu pooperacyjnego. W: Kübler A (red.). Anestezjologia Larsena. Wyd. 2 polskie. Wrocław: Urban \& Partner; 2002. 830-860.

5. Paszkiewicz-Mes E. Rola pielęgniarki w leczeniu bólu po zabiegu operacyjnym. Pielęg XXI w. 2011; 4 (37): 37-41.

6. Wróblewska IM, Dziechciaż M, Pietrucka M, Wróblewska Z, Błaszczuk J. Hospitalizacja jako czynnik stresogenny u pacjentów powyżej 60. roku życia - badania pilotażowe. Pielęg Chir Angiol. 2016; 3: 89-94. 
7. Khan RS, Skapinakis $P$, Ahmed K, Stefanou DC, Ashrafian $\mathrm{H}$, Darzi A, Athanasiou T. The association between preoperative pain catastrophizing and postoperative pain intensity in cardiac surgery patients. Pain Medicine. 2012; 13: 820-827.

8. Bajurna B, Mendyka L, Nowakowska I. Różnorodność problemów występujących w starszym wieku. Piel Pol. 2011; 1(39): 24-28.

9. Kuciel-Lewandowska JM, Laber WZ, Kierzek A, Paprocka-Borowicz M. Ocena poziomu lęku i depresji u pacjentów przed rehabilitacją kardiologiczną. Piel Zdr Publ. 2015; 3(3): 247-253.

10. Falkowska J, Szweda A, Garba P. Ocena skuteczności programu Szpital bez bólu - doświadczenia własne. Ból. 2011; 12 (2): 45-48.

11. Szczudłowski B, Płaszewska-Żywko L. Lokalizacja i natężenie bólu u chorych po zabiegach kardiochirurgicznych. Pielęg Chir Angiol. 2012; 4: 161-166.

12. Zalewska-Puchała J, Gaweł B, Majda A, Kamińska A. Skuteczność leczenia bólu pooperacyjnego u chorych po zabiegu torakotomii. Pielęg XXI w. 2014; 3(48): 11-16.

13. Deneka J, Głuszek S, Kozieł D. Chirurgiczne przyczyny bólu w klatce piersiowej. Stud Med. 2011; 21: 43-51.

14. Bolach E, Bolach B, Rachwalik W, Bialic M. Zmiany zakresu ruchów w stawach kręgosłupa i pojemności życiowej płuc oraz ocena bólu u pacjentów $z$ chorobą niedokrwienną po by-passach. Pedagogika Psychologia 2012; 3: 141-147.

15. Skokowska B, Bączyk G, Zembroń E, Bielawska A, Gacek L. Ocena jakości opieki pielęgniarskiej w zakresie bólu pooperacyjnego dokonywana przez chorych po zabiegach ortopedycznych. Piel Pol. 2016; 3(61): 367-375.
16. Sochacka A, Lewandowska A, Brukwicka I, Kopański Z, Wojciechowska M, Kurowski A. Zadania pielęgniarki w terapii bólu. JPHNMR. 2011; 3: 19-22.

17. Lisowska B, Smolak A, Wielgus M. Ocena pracy personelu medycznego $\mathrm{w}$ oddziale pooperacyjnym przez pacjentów po operacjach ortopedycznych. Anest Ratow. 2014; 8: 310-320.

18. Jurczak A, Kiryk A, Kotwas A, Pawlik J, Celewicz A, Szkup $M$, Grochans E. Ocena jakości opieki pielęgniarskiej w zakresie bólu pooperacyjnego. Fam Med Primary Care Rev. 2015; 17 ; 2: 107-110.

19. Juda M. Rola pielęgniarki w zwalczaniu bólu pooperacyjnego. Pielęg Pol. 2016; 3(57): 333-336.

Artykuł przyjęty do redakcji: 09.10.2018.

Artykuł przyjęty do publikacji: 01.02.2019.

Źródło finansowania: Praca nie jest finansowana z żadnego źródła. Konflikt interesów: Autorzy deklarują brak konfliktu interesów.

\author{
Adres do korespondencji: \\ Joanna Owsianowska \\ ul. Żołnierska 48 \\ 71-210 Szczecin \\ tel.: 914800910 \\ e-mail: jowsian@pum.edu.pl \\ Zakład Pielęgniarstwa Specjalistycznego, Wydział Nauk o Zdrowiu, \\ Pomorski Uniwersytet Medyczny w Szczecinie
}

